Administrative Issues Journal: Connecting Education, Practice, and Research, Summer 2016, Vol. 6, No. 1: 88-98. DOI: 10.5929/2016.6.1.5

\title{
Improved Student Outcomes in a Flipped Statistics Course
}

\author{
Laura Phillips, Ph. D. \\ Mark Phillips, Ph.D. \\ Abilene Christian University
}

\begin{abstract}
Statistics is a required competency in numerous college majors, but students frequently approach the topic with anxiety. This paper describes an undergraduate statistics course that was "flipped," with most of the content delivery moved online and class time devoted to application and practice. Students were given a menu of learning tools from which to choose and were free to utilize as many or as few as they felt was appropriate, giving them ownership of their learning experience and the opportunity to tailor the course to their personal needs. The classroom experience included brief segments of lecture but consisted primarily of exercises and peer-facilitation. Course grading was based solely on four exams, a comprehensive final exam, and a major end-of-course project. Student response to the format was somewhat bimodal. Comprehensive final exam grades were significantly higher (an average of almost one full letter grade), and course pass rates rose using the flipped course format.
\end{abstract}

Keywords: flipped classroom, statistics, collaborative learning, peer teaching

ndergraduate statistics courses can be frustrating for both student and teacher; generalized math anxiety or more focused "statisticophobia" (Dillon, 1982) are common among students who see little value in the course material. Roseth, Garfield, and Ben-Zvi (2008) argued persuasively that statistics education must be student-focused if outcomes are to be improved, suggesting that traditional lecture delivery may produce inferior results compared to more self-directed approaches. Sadler (1989, 1998) and others have long contended that students must be encouraged to own their educational process, taught to assess their own learning, and be capable of choosing appropriate learning tools for themselves. Michael Wesch (2009) took this idea even further, arguing that regardless of the specific subject being taught, the more important competency of how to approach knowledge and how to build understanding can only be achieved by practice.

While learning statistics is frequently a solitary affair, numerous individuals from multiple disciplines have called for greater use of collaborative learning in statistics education (Hogg, 1992, Lovett \& Greenhouse, 2002). The 2005 GAISE guidelines state that statistics educators should lecture less and facilitate more exercises, group problem-solving, and discussion (Franklin \& Garfield, 2006). The course redesign 
described in this paper was undertaken with the objective of improving student learning outcomes both in terms of technical proficiency and in terms of student ability to learn in general.

\section{Scope and Context}

The business statistics course described in this paper is an undergraduate, non-calculus course typically taken during the sophomore or junior year. Enrollment generally includes up to $10 \%$ students majoring in nursing, communication, and other fields. Course topics include the organization and management of data, scales of measurement, sampling and surveying schemes, statistical graphics, descriptive statistical measures of central tendency and variability, special discrete and continuous probability distributions, elementary techniques of statistical estimation and inference, correlation, and Chi-square analysis. The course discusses uses of statistical methods in various settings and provides students with hands-on experience in using computer technology to summarize, analyze, and interpret data sets.

The course is taught in a large computer lab by one instructor and one or more student assistants, depending on enrollment. Course prerequisites are completion of Finite Mathematics and a familiarity with general probability and Microsoft Excel. The institution is a private four-year liberal arts college with an enrollment of approximately 4000.

\section{Definitions and Concepts}

Collaborative learning and peer instruction describe course environments in which students collaborate to learn and assist others in learning. First described in the 1990's by Eric Mazur and others (King, 1993), collaborative learning models attempt to transform the role of the instructor from broadcaster of information (which is then dutifully copied down) to facilitator of learning. By pushing students to consider questions and come to their own answers (and forcing them to defend these answers to their peers), this approach is believed to encourage deeper analysis and promote greater understanding (e.g. Fink, 2004). Advocates of this approach argue that it promotes engagement and minimizes surface-level thinking in the classroom. A recent meta-analysis demonstrated that collaborative and cooperative learning significantly improved students' performance in statistics courses (Kalaian \& Kasim, 2014).

A related but distinct concept is the flipped classroom. Emerging alongside the growth of online learning tools and broader access to broadband internet during the 1990's (Lage, Platt, \& Treglia, 2000), flipped courses attempt to reverse the traditional learning model in which students receive information in class and then practice or review it outside of class. As online tools have matured, information delivery outside the classroom has become much more practical. In a typical flipped course, students are first exposed to material prior to class via video, readings, or other electronically delivered media. Class time is then devoted to applying the material with the assistance of the teacher, whose role is broadly transformed from "from sage on the stage to guide on the side" (King, 1993). Although distinct from one another, peer instruction and flipped classroom approaches are naturally complimentary approaches, and the terms are sometimes (incorrectly) used interchangeably. The present discussion describes a course that utilizes peer instruction methods, and a flipped classroom philosophy. 


\section{Course Structure and Conduct}

The course in its current form is the result of a gradual evolution and will likely continue to evolve. The course was originally structured as a traditional lecture, moving through an intermediate phase to its current flipped configuration. Table 1 lists the elements of the course and provides brief descriptions of each item. A more expanded description is subsequently provided for each item as they are used in the redesigned course.

Table 1

Course Elements and Grade Impact by Class Format

\begin{tabular}{lll}
\hline Item & Original Format & Current Format \\
\hline Lectures & Yes & No \\
Daily homework & Mandatory* & Optional (small credit offered for attempting work) \\
Daily quizzes & In class, mandatory* & On-line, optional \\
Problem-solving during class & No & Yes \\
Podcasts & No & Yes \\
PowerPoint slides & In class, not posted & Yes \\
Intermediate exams & Yes* & Yes* \\
Course project & Yes* & Yes* \\
Evening exam reviews & Optional & Optional \\
Final exam (comprehensive) & Yes & Yes \\
\hline
\end{tabular}

Note. The asterisks indicate "included in the course grade calculation."

Outside-of-class Activities (available online prior to class)

- Daily homework: students are provided a short practice problem; in class they receive credit for attempting it and feedback on the correctness of their solution

- Daily quizzes: a series of questions over course material; students are given the questions and the solutions for use outside class

- Podcast: an approximately 30-minute video with narration and screen-capture demonstrating step-by-step how to use Excel and the MegaStat package to perform the required analysis

- PowerPoint slides: a slide presentation discussing the class topic

- Evening exam review sessions: a one-to-two hour session prior to each exam in which students solve problems, ask questions, and solidify their understanding of the material

- Course project: a group exercise applying the course tools and concepts in a practical exercises

\section{In-class Activities}

- Problem-solving: students work alone, with peers, or with help from the instructor to practice 
their skills, completing problems (that would traditionally have been homework) after the in-class lecture

- Intermediate exams: application tests covering course material up to that point (all are comprehensive)

- Final exam (comprehensive): assessment of the student's ability to perform statistical analysis and interpret data and findings

The new course model includes several notable changes, while preserving key elements of the old. First, assessment remains rigorous, with a comprehensive final (which counts double) and intermediate exams making up a large part of the course grade. Second, the number of learning tools available to students has increased, while the requirement to use any particular tool has been removed. This change serves to place the responsibility for fashioning the learning experience on the student, rather than the teacher. It is also more efficient, letting students opt out of exercises that are unneeded and eliminating superfluous grading by the teacher. It may be generally assumed from the current course structure that a student who arrives unprepared will learn relatively little in class, since the teacher does not repeat the material already presented in the online format. Further, students who are unwilling or unable to take responsibility for their own learning experience will likely find this format less pleasant than a traditional course.

A typical class meeting begins with the teacher making brief announcements about upcoming events. This is followed by a period of discussion, in which random students are chosen to ask questions or share something learned from their outside-of-class preparation. By having the students ask, rather than answer questions, the instructor reduces stress for students who are prepared; unprepared students generally find it difficult to ask a meaningful question. The remainder of the class meeting is devoted to working practice problems, which become available online at the start of the class meeting.

The class environment is designed to encourage collaboration; music plays, and the teacher and teaching assistant circulate through the room. Students generally discuss questions with classmates. If classmates cannot help, students can ask a peer teacher (previous enrollees who scored unusually well) for assistance. At this point, students have had two opportunities to receive assistance without consulting the teacher at all, which encourages reluctant students to seek help. Because the teacher is circulating, rather than standing at the front, she frequently identifies students in need of assistance before they realize their situation.

\section{Learner-designed Learning}

The course design allows students to choose individually appropriate learning tools. Because students enter the course at a variety of skill levels, the traditional class experience is frequently either boredom with a class that moves too slowly or frustration with one that moves too quickly. Motivated students in the redesigned course take a variety of paths to achieve their learning goals. In one extreme case, a student with existing statistics competency attended class only on exam days and earned a grade of "A." At the other extreme are students who make use of all the outside learning tools as well as attending class and review sessions in order to pass. 
The flipped class enables motivated students to invest additional time that they would not have had in a traditional course, using course materials that include podcasts, quizzes, practice problems, and slides as many times as they wish. In one case, a student whose previous morning class frequently ended early would come to the lab and begin working with the students in the earlier section. In another case, a student who often completed the day's class meeting without a full grasp of the material would simply return for the afternoon section and work problems with those students. Students who are enabled to structure their own course experience are less likely to resent the time they invest and more likely to embrace the learning process.

\section{Outcomes}

The present study attempts to answer two broad questions: how do students perceive the general class format and the specific learning tools provided, and what impact does the new format have on student learning? Student perceptions of a course directly and indirectly impact their learning experience. Students were asked to assess the usefulness of the learning tools on a 1-5 scale ( $1=$ not at all useful, $5=$ extremely useful). Responses are summarized in Figure 1.

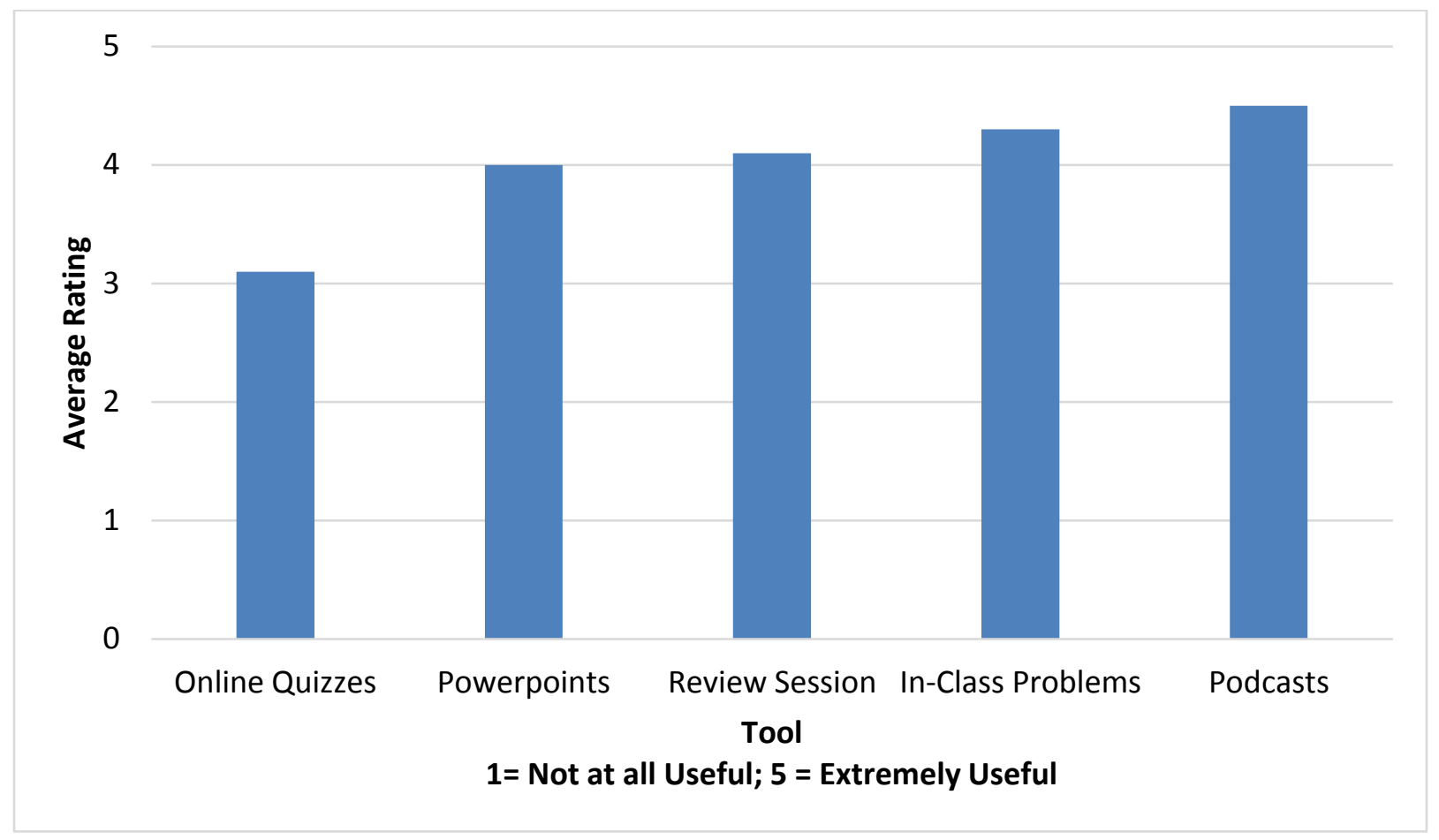

Figure 1. Student assessment of learning tool usefulness. 
Students were also asked to assess the relationship between specific tool use and success in the course on a 1-5 scale. Responses are summarized in Figure 2.

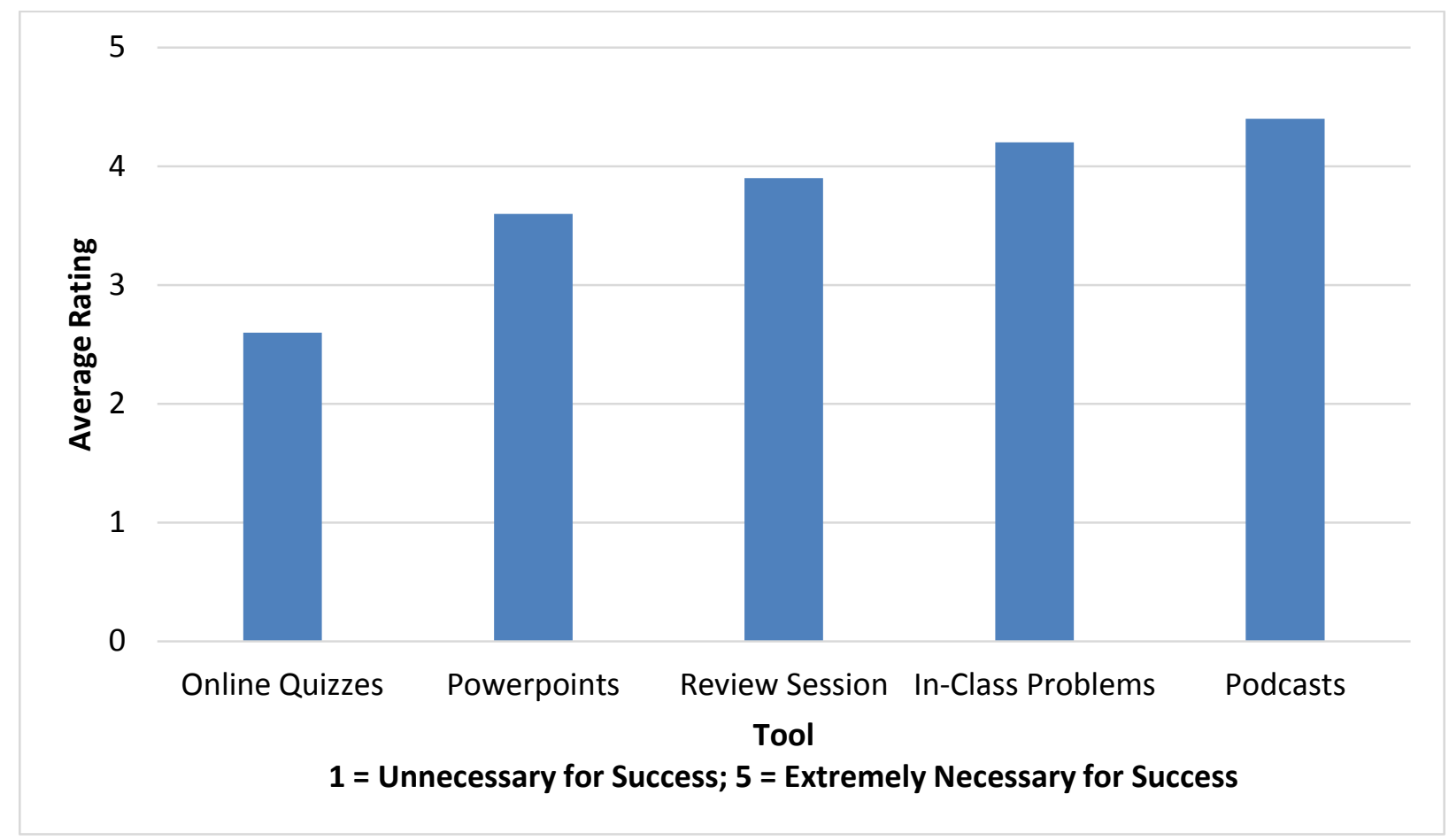

Figure 2. Student assessment of learning tool necessity for success.

Responses to the two items were relatively consistent, with podcasts and in-class problem-solving ranked at the top of both lists. Online quizzes ranked last in both lists; anecdotal interactions suggest that relatively few students chose to utilize the online quizzes.

Student preferences may not fully reflect the utility of a given tool, since all students did not actually use all tools. Further, the novelty of the course format and students' inexperience with this course design may mean their responses do not reflect the actual utility of a given tool. However their perceptions and attitudes play an important role in their behavior.

Students were also asked to assess the course format compared to a traditional course delivery model. The responses suggest a somewhat mixed response to the format change, with $10.7 \%$ definitely and $32.1 \%$ somewhat preferring the new format, $21.4 \%$ neutral, and the remainder preferring the traditional class format. Given the relative novelty of the format, the fact that $43 \%$ percent preferred the new mode, in what was for most their first exposure to it, is encouraging. Further research should be devoted to determining student perceptions of the flipped class format once they have more experience with it. These responses are summarized in Figure 3. 


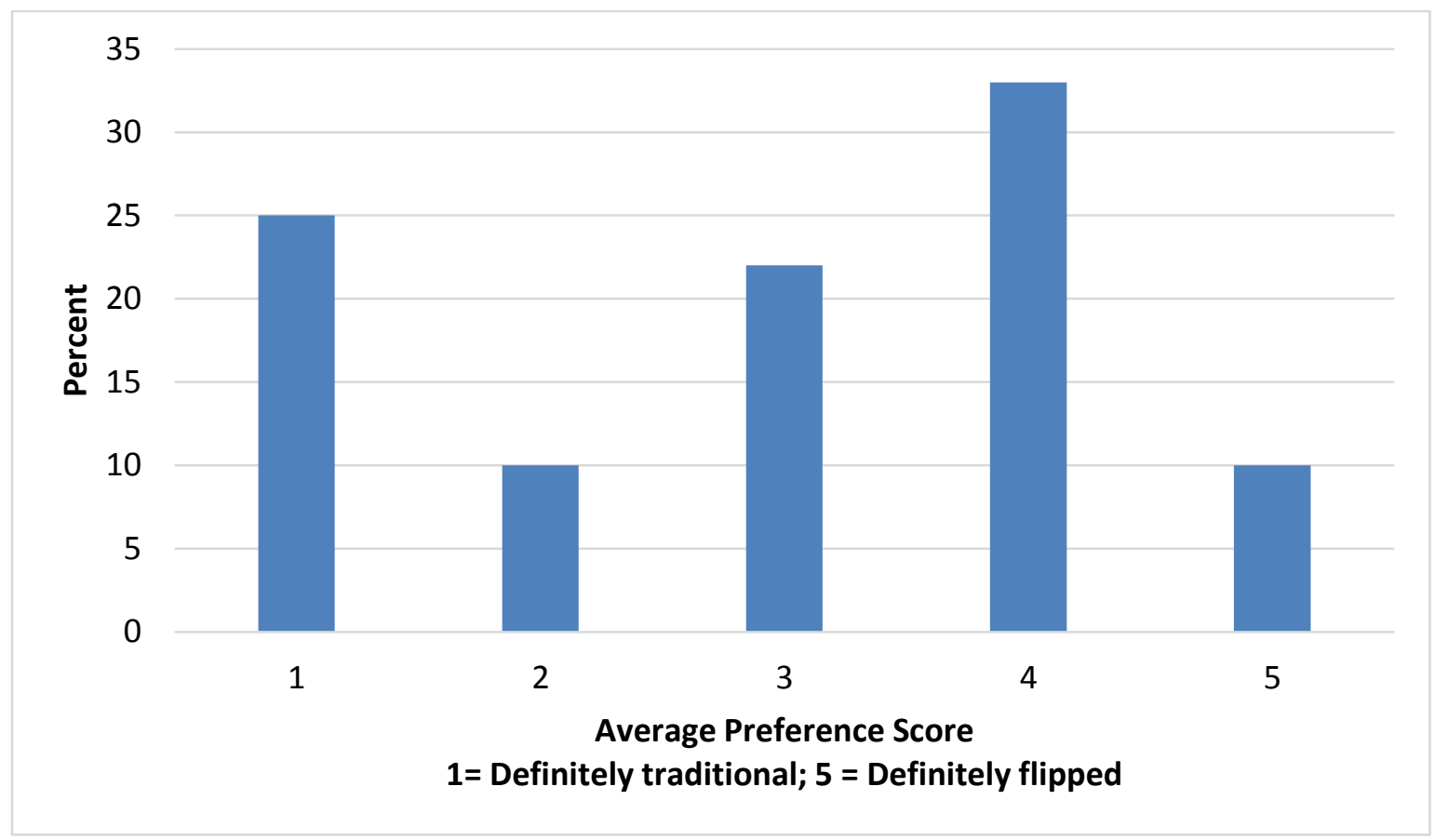

Figure 3. Student format preference.

The study authors suspected that student ability might be related to student assessment of the new format. Course format preference and pre-course GPA were not significantly correlated $(p=.251)$, while course format preference and course final grade were significantly correlated $(p<.01)$. Causality cannot be established from this analysis.

\section{Learning Outcomes}

The ultimate test of any teaching method is whether students learn the material. In the present course, we attempted to teach both self-management of learning and practical skills related to statistical analysis. The former objective is difficult to quantify, since it is highly subjective. The ability to perform statistical analysis, however, is more easily measured.

Although not a perfect measure, the course grade offers a reasonable assessment of subject mastery. In both the traditional and flipped formats, exams (including a comprehensive final) make up a large part of the course average. In addition, the fact that the course was delivered by the same teacher suggests similar levels of rigor and difficulty. Finally, course grades, for better or worse, are ultimately the measure that count, both from the student's and the institution's perspective.

Course grade distributions for both course formats are presented in Figure 4. 


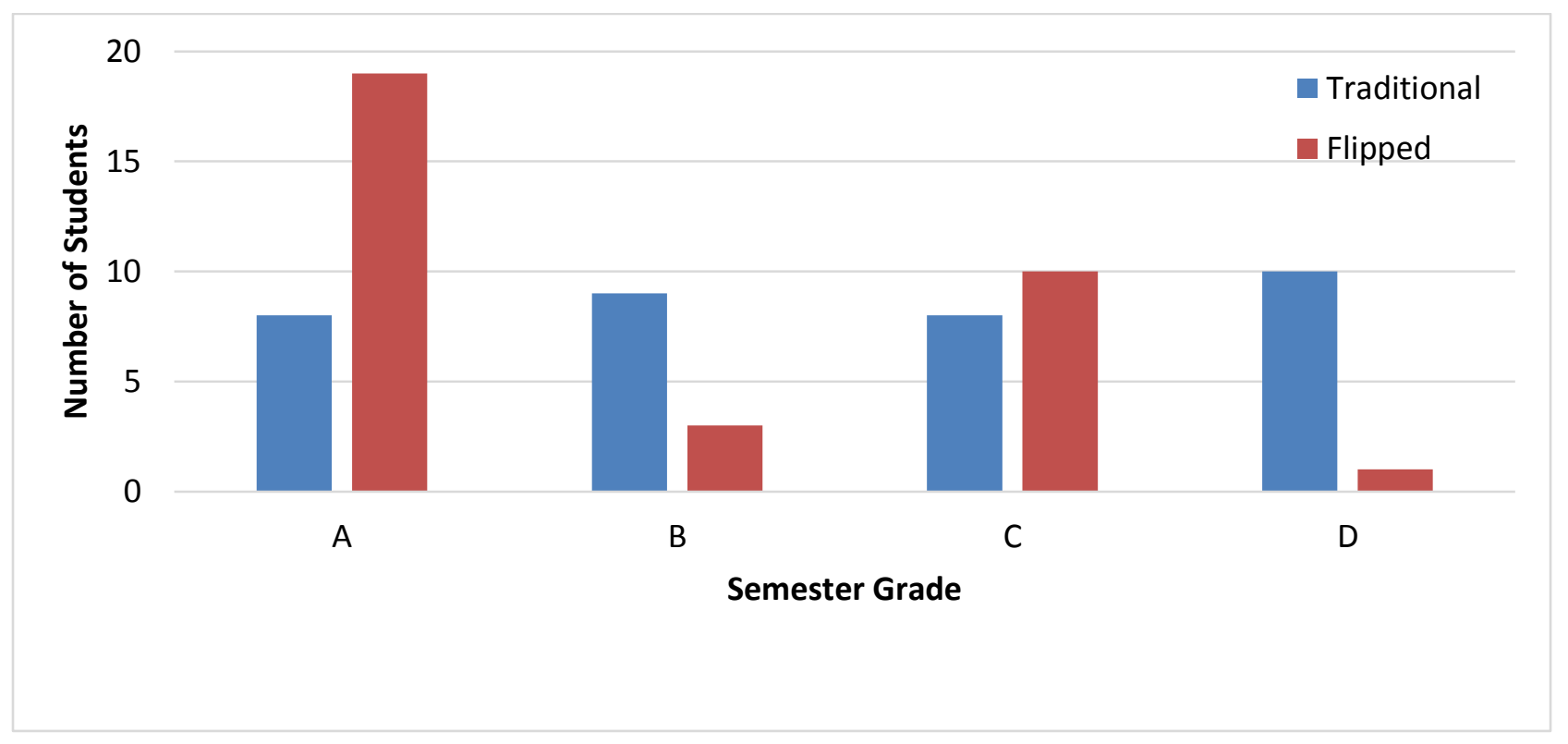

Figure 4. Grade distribution by course format.

The grade distribution in the traditional course was relatively flat, with $25 \%$ more failures (grade of D or F) than A's. The grade distribution in the flipped course tilted noticeably toward the high end, with the percentage of students earning grades of " $A$ " more than doubling and a $90 \%$ reduction in failing grades. The average course grade improved from 2.29 to 3.20 , almost a full letter increase (Table 2).

Table 2

Grade Distribution and Letter Grade by Course Format

\begin{tabular}{ccc}
\hline Letter Grade & Traditional Format & Flipped Format \\
\hline A & 8 & 19 \\
B & 9 & 3 \\
C & 8 & 10 \\
D/F & 10 & 1 \\
\hline
\end{tabular}

Course design changes are often targeted at improving outcomes for poorly performing students, and the reduction in failing grades suggests this design change achieved that objective. Beyond helping struggling students, the move to a flipped format also appears to have moved good students toward being superior students, a somewhat more elusive outcome. Regardless of a student's level of capability, the new format places the responsibility for learning more clearly in the hands of the student. Stronger students no longer need to sit through lectures they do not need, while weaker students have $24 / 7$ access to course materials to use and re-use to master the material. 


\section{Additional Analysis}

The single most accurate assessment of overall learning in this course is the student's grade on the comprehensive final exam, which accounts for $29 \%$ of the course grade. In the flipped class format, all of the learning tools are optional; grades are assigned only for the four unit exams (each comprehensive up to that point in the semester), the group project, and the comprehensive final exam. With so many tools available whenever and wherever the student wants to use them, the hope is that learning rests in the hands of the students. It is possible, however, that students who succeed in the format succeed simply because they are better students and not because of how they use the available tools.

Multiple regression was utilized to assess the extent to which pre-stats GPA and use of the available tools predict grades on the comprehensive final exam. The course tools incorporated as independent variables included

- Number of class periods attended

- Number of online quizzes taken

- Number of PowerPoint presentations viewed

- Number of review sessions attended (maximum of five-one before each exam)

- Number of review sheets accessed (maximum of five-one before each exam)

- Number of podcasts viewed before working in-class homework problems on the topic

- Number of podcasts viewed later in the unit as a review for an exam

Analysis of the data confirms the assumptions related to multicollinearity, normality, linearity, and homoscedasticity. The total variance explained by the full model was $41.3 \%, F(8,24)=3.817, p=.005$. The only variable that was statistically significant was the number of podcasts viewed before working in-class homework problems on the topic (beta $=.520, p=.028$ ). According to this analysis, staying caught up with the prep material was the only significant predictor of final exam grade (i.e. GPA was not statistically significant in this model). Based on this model-from a prescriptive standpoint-increasing the number of podcasts watched "on time" by 5.6 (one standard deviation) would result in a 10.8 point increase on the final exam -slightly more than one letter grade.

This outcome is good news for students who are afraid of statistics or who are uncomfortable with their quantitative skills. Students, regardless of their pre-statistics GPA, have the potential to significantly boost their learning in the course, simply by staying caught up with the prep work for each class meeting.

\section{Summary}

Teaching techniques that potentially improve average course grades by one full letter are rare. The use of a collaborative learning environment, married to online tools and delivered via a flipped classroom model, incorporates several complementary tools to create a distinctly different student learning experience. This 
finding is consistent with previous work on each of these techniques in general, and specifically in terms of how collaborative learning appears to improve student outcomes in learning statistics.

Like any other meaningful change, this course redesign required extensive work on the part of the teacher. As flipped class practitioners note, the creation of online tools such as quizzes and podcasts is timeconsuming and may appear overwhelming; these resources, however, should be viewed as an investment, with the initial outlay paying dividends for many future generations of students.

In closing, it seems reasonable to suggest that statistics teachers take their own advice and collaborate to help one another implement improved teaching techniques and methods, rather than flying solo. Like our students we tend to work alone, rather than collaborating. If learning statistics is more productive in community, perhaps learning to teach statistics will be as well.

\section{References}

Dillon, K. M. (1982). Statisticophobia. Teaching of Psychology, 9, 117.

Fink, L. D. (2004), "Beyond Small Groups: Harnessing the Extraordinary Power of Learning Teams," in L. Michaelsen, A. Knight, and D. Fink (Eds.), Team-based learning: A transformative use of small groups (pp. 1-36).VA: Stylus Publishing.

Franklin, C., \& Garfield, J. B. (2006). The GAISE Project: Developing statistics education guidelines for pre K-12 and college courses. In G. Burrill (Ed.), Thinking and reasoning with data and chance: 2006 NCTM yearbook (pp.435-375). Reston, VA: National Council of Teachers of Mathematics.

Kalaian, S. A., \& Kasim, R. M. (2014). A meta-analytic review of studies of the effectiveness of smallgroup learning methods on statistics achievement. Journal of Statistics Education, 22(1). Retrieved from www.amstat.org/publications/ise/v22n1/kalaian.pdf

King, A. (1993). From sage on the stage to guide on the side. College Teaching, 41(1), 30-35.

Lage, M., Platt, G., \& Treglia, M. (2000). Inverting the classroom: A gateway to creating an inclusive learning environment. The Journal of Economic Education, 31(1), 30-43.

Roseth, C. J., Garfield, J. B., \& Ben-Zvi, D. (2008). Collaboration in learning and teaching statistics. Journal of Statistics Education 16(1). Retrieved from http://www.amstat.org/publications Lise/v16n1/roseth.html

Sadler, D. R. (1989). Formative assessment and the design of instructional systems. Instructional Science, 18(2), 115-126.

Sadler, D. R. (1998). Formative assessment: Revisiting the territory. Assessment in Education, 5(1), 77-84.

Wesch, M. (2014, September 9). From knowledgeable to knowledge-able: Learning in new media environments. The Academic Commons for the Liberal Education Community. Retrieved from http://www.academiccommons.org/2014/09/09/from-knowledgable-to-knowledge- 
able-learning-in-new-media-environments/

\section{About the Authors}

Laura Phillips (Icp05a@acu.edu) is an Associate Professor of Management Sciences at Abilene Christian University. Her research interests include social entrepreneurship and teaching innovation.

Mark Phillips* (mhp04a@acu.edu) is Department Chair and Professor of Management Sciences at Abilene Christian University. His research interests include teaching innovation and organizational behavior.

*corresponding author 